\title{
Effectof Educational Intervention Based on the Health Belief Model on Preventive Behavior of Maternity Nurses towards COVID-19 and Its Vaccination Sabah Lofty Mohamed El Sayed ${ }^{1}$, Amira Mohammed Salama ${ }^{2}$, Amany S. Badawy ${ }^{3}$ \\ ${ }^{1}$ Assistant professor, Obstetrics and Gynaecological Nursing, Faculty of Nursing,Zagazig University \\ ${ }^{2}$ Assistant professor, Obstetrics and Gynaecological Nursing, Faculty of Nursing, Benha University, Egypt \\ ${ }^{3}$ Assistant professor, Obstetrics and Gynaecological Nursing, Faculty of Nursing,Zagazig University
}

\begin{abstract}
Background: Egypt has implemented stringent preventive and precautionary steps against COVID-19 to protect citizens. COVID-19 has a high risk of human-to-human transmission, and millions of people worldwide have suffered negative consequences. Aim:This study aimed to find out how an educational intervention based on the health belief model affects the maternity nurses' behavior towards COVID-19 and its vaccine.Subjects and
\end{abstract} Method:Setting:In the Department of Obstetrics at Zagazig University Hospital.Subjects:An interventional study was conducted via convenience sampling on all nurses who provided care to women during childbirth using the following tools; 1) Nurses' demographic features; 2) Nurses' understanding of the COVID-19 pandemic; 3) The health belief model; and 4) Nurses' COVID-19 pandemic prevention behavior.Results: The findings revealed a statistically significant positive correlation between nurses' Covid-19 knowledge and educational intervention ( $\mathrm{P}$ 0.000). Before and after the educational intervention, there are statistically significant differences in the mean scores and level of the health belief model (P 0.000). A highly significant positive correlation between the health belief model and the intervention $(r=0.89 \& \mathrm{p} 0.000)$ was also found.Conclusion:Aneducational intervention based on the health beliefs model has significantly improved knowledge and preventive behavior of nurses towards COVID19.Recommendations:Workers in the health sector should be targeted for health-education interventions since they are at a higher risk of getting COVID-19.

Keywords:COVID-19, Health Education Interventions, Health Belief Model, Knowledge, Preventive Behavior. 


\section{Introduction}

Following its appearance in Wuhan, China in 2019, the coronavirus infection (COVID-19) has a high risk of human-tohuman transmission, and millions of people worldwide have suffered negative consequences (Awadasseid et al., 2020).

It is widely diagnosed $(14,012,449$ persons globally), and it can be severe and fatal (596,158 deaths globally) (Taiwan Centers for Disease Control, 2020) [1]. It has severe physical, psychological, emotional, and social consequences (Dey SK et al. 2020) [2]. COVID-19 knowledge, related health beliefs, self-efficacy, and defensive behaviors are all extremely important for lowering infection rates, lowering mortality, and maintaining people's health and quality of life. (Kang et al., 2020)[3]. COVID-19 can take from 1 to 14 days to incubate, and it can last anywhere from a few weeks to several months. It causes contact infections and human-to-human droplets (Wang et al., 2020)[4]. It's also possible to develop COVID-19 with or without symptoms (Sun et al., 2020)[5].Chest tightness, headache, difficulty breathing, fever $>38^{\circ} \mathrm{C}$, sneezing, runny nose, stuffy nose, cough, nausea, abdominal pain, diarrhea, muscle aches, weakness, and overall weakness are some of the symptoms that can occur
(Keesara et al., 2020). In addition, people are more likely to experience physical, psychological, emotional, and social issues, such as sleeplessness, stress, anxiety, depression, social support, coping issues, and exhaustion (Tu et al., 2020)[6].

Nurses must have the adequacy of certain personal self-protection measures, such as hand washing, temperature taking, maskwearing, open doorways and windows, and maintaining a strategic distance from entry into premises, as their knowledge of these indications and their associated effects of COVID-19 grows. Hand sanitizer with 60-75 percent alcohol should be used in public places, and disinfectant should be used on frequently used surfaces (Tourer et al., 2020)[7].

Perceived susceptibility, perceived severity, perceived advantages, perceived barriers, and action cues are all part of the health belief model's framework when it comes to the implementation and maintenance of healthy habits. People's health and infection are linked to their beliefs about their well-being in terms of perceived helplessness, seriousness, benefits, and barriers to sickness, as evidenced by preventative behaviors and behavioral intents. Healthy behaviors are important and have a significant impact 
on people's health, thus they must be practiced and maintained to protect and promote people's welfare (Mukhtar, 2020)[8].

\section{Significance of the study}

As a recommendation for preventing the spread of COVID-19, the World Wellbeing Organization promotes ensuring health care workers (HCWs) and patients' close contacts by following necessary preventive measures such as regular hand washing, social distancing, and respiratory hygiene (covering mouth and nose while coughing or sneezing) (WHO, 2020)[9].

HCWs are at the forefront of COVID-19 broad defenses and are exposed to not just disease caused by COVID-19 as a result of their visits to infected persons, but also emotional stress, long working hours, word-related stigma, and aggressive behaviors. (WHO, 2020; Gan et al., 2020)[10-11]. Overcrowding, a lack of isolation facilities, and a dirty environment exacerbate infectious disease transmission among HCWs, which is likely improved by inadequate awareness and information of disease control methods among HCWs. (Wu \&McGoogan, 2020)[12]. Inadequate information and inappropriate attitudes among HCWs can have a direct impact on nursing practices, resulting in delayed diagnosis and disease spread (McEachan

et al., 2016)[13].

\section{Aim of the study}

This study aimed to find out how educational interventions based on the health belief model affect the maternity nurses' behavior towards COVID-19 and its vaccine.

\section{Study hypothesis}

At this important period, a health belief model-based educational intervention is expected to improve maternity nurses' awareness and practice regarding COVID-19 and its vaccination.

\section{Subjectsand Method}

\section{Studydesign}

To achieve the study's aim, a quasiexperimental design was used.

\section{Study setting and period}

The study took place in the obstetrics building of Zagazig University Hospitals from May 1 to 30, 2021. Because it is the principal hospital in Sharkia Governorate, this building was chosen. It has five floors, with reception and administrative offices on the first floor, a postpartum care unit on the second floor, and a highrisk care unit with three rooms, ten beds, and an intensive care unit on the third floor. A nursing staff room, a bathroom, and a teaching hall are also available. The newborn intensive care unit, birth 
examination room, and cardiogram

(CTG) examination room are located on the fourth floor, while operation rooms are located on the fifth floor. It provides free treatment to all levels of society in the governorate, as well as the control and prevention of COVID-19.

\section{Study sample and Subjects criteria}

Using convenience sampling, all available nurses (82 nurses) who provided nursing care to women during childbirth were selected.

\section{Data collection tools}

(I) Nurses' sociodemographic

characteristics: age (year), level of education, years of experience, place of residence, and source of information about covid-19.

(II)Nurses' knowledge of the COVID19 pandemic. It was developed by the researchersafter reviewing the related literature. It consisted of 29 questions that covered the most frequent information on COVID 19, including the route of transmission and ways to avoid infection.

\section{Nurses' Knowledge grading system}

Each question was answered with one of the following options: yes, no, or don't know. Yes, for the ones that require a correct answer, and no, for the others. This was divided into three categories: poor, average, and good.
(III) Health Beliefs Model. It was adapted from (Khoramabadi.,2016)[14].Perceived susceptibility (6 items), perceived benefits ( 8 items), perceived severity (6 items), perceived barriers (15 parts), cues for action (10 items), and self-efficacy (10 items) were among the 51 items.

\section{Health Beliefs Model scoring system}

The nurse had selected one of five selections for each item: Strong Agree $=4$, Agree $=3$, no idea $=2$, Disagree $=1$, Strongly Disagree $=0$. These were divided into three categories: low, moderate, and high.

\section{(IV) Nurses' preventive behavior in the face of the COVID-19 pandemic.}

It included 14 items; hand washing, duration, drying method, vaccination, standard recommendations, injection, using alcohol-based disinfectants and disinfecting surfaces, and herbal supplements as a preventative measure, and others.

Nurses' preventive behavior scoring system

There are five selections for each item ("always" with a score of 4 , often with a score of 3 , sometimes with a score of 2 , rarely with a score of 1 , 
and "never" with a score of 0 ). The

score was divided into three

categories: low, moderate, and high.

\section{Validity}

The tools were presented to four professors of nursing sciences for reviewing and make the necessary adjustments.

\section{Reliability}

A test and a re-test were used to determine the questionnaire's reliability. Knowledge had a correlation coefficient of 0.69 , the health belief model had a correlation coefficient of 0.83 , and preventative activity had a correlation coefficient of 0.92 .

\section{Validity}

The tools were distributed to 4 professors of nursing sciences and studying the comments and adopting the necessary changes by the experts.

\section{Pilot study}

A pilot study was conducted on a sample of 8 nurses $(10 \%)$ to evaluate the questionnaires' validity and reliability, but no changes were made. This research sample was used in the research.

\section{Data Collection procedure}

The study was carried out in three phases.

1. The assessment phase of the intervention.
The participants were greeted by a researcher who introduced herselfand discussed the study's scope. Then, nurses in the hospital filled out pretest questionnaires.

\section{The implementation phase of the intervention.}

Pre-test data and the HBM frame were used to develop an educational program. During the two shifts, the training session was delivered in three 45-minute sessions in hospital educational courses. Sessions took place in person in the mornings and afternoons in shifts. Each session was focused onusing HBM parts and components (perceived susceptibility, perceived benefits, perceived severity, perceived barriers, cues for action, selfefficacy). The program's content centered on Covid-19, its vaccination, the importance of safety precautions, taking precautions, and preventing Covid-19 spread using HBM parts and components. Based on pretest results that showed a high level of hospital risk among nursing staff, the study intended to remove barriers to healthy behaviors in study content and teach nurses of the benefits of healthy behaviors. At the end of each session, a few minutes were set out for questions and responses, as well as for overcoming the lack of clarity. The nurses were provided a booklet based on 
the resources and publications that

included information about COVID-19 and vaccination to encourage them to practice healthy behaviors. Furthermore, the benefits and drawbacks of healthy practices are discussed, as well as a variety of strategies for overcoming perceived

barriers.Using educational booklets, grou ps and individuals were educated face-toface throughout this phase.

3. Evaluation phase. A post-assessment was conducted after one month of the educational program for nurses, the nurses completed the questionnaire as a pre-assessment. After one month of the educational program for nurses, a post-assessment was conducted in which the nurses completed the questionnaire as a pre-assessment.

\section{Ethical considerations}

The ethical committee that approved the study was the Faculty of Nursing, Zagazig University, with the ethics approval number "NUR2021". The anonymity of study participants was secured throughout the study by keeping participant information private and requiring individuals to give truthful replies. This was a completely voluntary and unpaid event.

\section{Data analysis}

Data were encoded and analyzed using the Statistical Package for Social Sciences (SPSS) version 22. Descriptive analyzes were considered as the means and standard deviations (SD) of the numerical data and the number and percentage of the qualitative data. The Chi-square test was used to compare qualitative variables. A comparison mean of knowledge, HBM, and preventive behavior scores was made using the paired t-test. Pearson correlation of knowledge, HBM, and preventive behavior scores was performed. $\mathrm{P} \leq 0.05$ was considered statistically significant 


\section{Results}

Table 1 reveals that $56.1 \%$ of the nurses were between the ages of 22 and 28, with an average age of $29.08 \pm 6.0$ years. With regards to education level and years of experience, $46.3 \%$, and $56.1 \%$, had enrolled in a nursing diploma and had 1-9 years of experience, respectively. In addition, $74.4 \%$ of them were from urban places.

Table 2 shows that there is a statistically significant difference in the mean scores before and after educational intervention in nurses' knowledge of covid-19 ( $\mathrm{t}=$ $90.542 \& \mathrm{P}<0.0001)$. Also,there is a statistically significant difference in nurses' knowledge level of covid-19 before and after the educational intervention $\left(\mathrm{X}^{2}=32.33\right.$ \& $\left.\mathrm{P}<0.0001\right)$. Moreover, this table demonstrates a positive significant correlation $(r=0.365$ $\& \mathrm{P}<0.0001)$ between nurses' knowledge of Covid-19 and educational intervention (Table 2).

Figure 1 demonstrates that $41.9 \%$ and 32 $.4 \%$ of nurses, respectively, had known a bout covid-19 via television and social media.

Table 3 shows that the mean scores of the health belief model before and after the educational intervention are significantly different $(\mathrm{P}<0.000)$.

Table 4 shows that there is a statistically significant difference in the level of health belief before and after educational intervention $(\mathrm{P}<0.000)$.

Table 5 demonstrates that, there is a highly positive significant correlation between the health belief model and the intervention ( $\mathrm{P}$ 0.000), excluding perceived benefits ( $\mathrm{P}=0.273$ ).

Table 6 shows that the mean and level of total health belief model scores about Covid-19 and educational intervention are statistically different $\left(\mathrm{t}=89.44 \& \mathrm{X}^{2}\right.$ $=37.831 ; \mathrm{P}<0.000$, respectively). As well as, the above table reveals that the health belief model and intervention have a highly positive significant correlation $(\mathrm{r}$ $=0.81 \& \mathrm{P}<0.000)$.

Table 7 shows that there is a statistically significant difference between the mean scores and level of nurses' knowledge on how to avoid and control Covid-19 before and after the educational intervention $(\mathrm{t}=$ $\left.70.568 \quad \& \quad \mathrm{X}^{2}=56.119 ; \quad \mathrm{P}<0.000\right)$, respectively. Furthermore, the above table shows that the health belief model and intervention have a highly positive significant correlation $(r=0.89 \& \mathrm{P}<$ $0.000)$. 
Table (1): Sociodemographic characteristics of nurses $(n=82)$

\begin{tabular}{|c|c|c|}
\hline $\begin{array}{l}\text { Socio-demographic } \\
\text { characteristics }\end{array}$ & Number & Percent \\
\hline \multicolumn{3}{|l|}{ Age/ year } \\
\hline ○ $22-28$ & 46 & 56.1 \\
\hline ○ $29-34$ & 16 & 19.5 \\
\hline ○ $35-40$ & 20 & 24.4 \\
\hline Mean \pm SD & \multicolumn{2}{|c|}{$\frac{1}{29.08 \pm 6.00}$} \\
\hline \multicolumn{3}{|l|}{ Level of education } \\
\hline ○ Diploma of nursing & 38 & 46.3 \\
\hline o Bachelor in Nursing & 8 & 9.7 \\
\hline - Post Graduate & 36 & 43.0 \\
\hline \multicolumn{3}{|l|}{ Experience Years } \\
\hline$\circ \quad 1-9$ & 46 & 56.1 \\
\hline ○ $10-18$ & 12 & 14.6 \\
\hline ○ $19-25$ & 24 & 29.3 \\
\hline Mean \pm SD & \multicolumn{2}{|l|}{$9.84 \pm 7.9$} \\
\hline \multicolumn{3}{|l|}{ Place of resident } \\
\hline$\circ$ Rural & 61 & 74.4 \\
\hline ○ Urban & 21 & 25.6 \\
\hline
\end{tabular}

Table 2: Nurses' knowledge scores about Covid-19 before and after the intervention $(\mathrm{n}=$ 82)

\begin{tabular}{|c|c|c|c|c|c|c|}
\hline \multirow{2}{*}{$\begin{array}{l}\text { Nurses Knowledge } \\
\text { about Covid-19 }\end{array}$} & \multicolumn{4}{|c|}{ Educational intervention } & \multirow{2}{*}{ Test } & \multirow[t]{2}{*}{ P-value } \\
\hline & \multicolumn{2}{|c|}{ Before } & \multicolumn{2}{|c|}{ After } & & \\
\hline Mean \pm SD & \multicolumn{2}{|c|}{$24.95 \pm 3.4$} & \multicolumn{2}{|c|}{$28.06 \pm 3.42$} & $\mathrm{t}=90.54$ & $<0.0001^{* *}$ \\
\hline \multicolumn{5}{|l|}{ Level } & \multirow{4}{*}{$X^{2}=32.33$} & \multirow{4}{*}{$<0.0001^{* *}$} \\
\hline Poor (no, \%) & 38 & $46.3 \%$ & 23 & $28.0 \%$ & & \\
\hline Average & 40 & $48.8 \%$ & 24 & $29.3 \%$ & & \\
\hline Good & 4 & $4.9 \%$ & 35 & $42.7 \%$ & & \\
\hline \multicolumn{5}{|l|}{ Correlation } & $r=0.365$ & $<0.0001^{* * *}$ \\
\hline
\end{tabular}

*. The Chi-square statistic is significant at the .05 level. $\quad$ r: Pearson Correlation

** Correlation is significant at the 0.01 level 


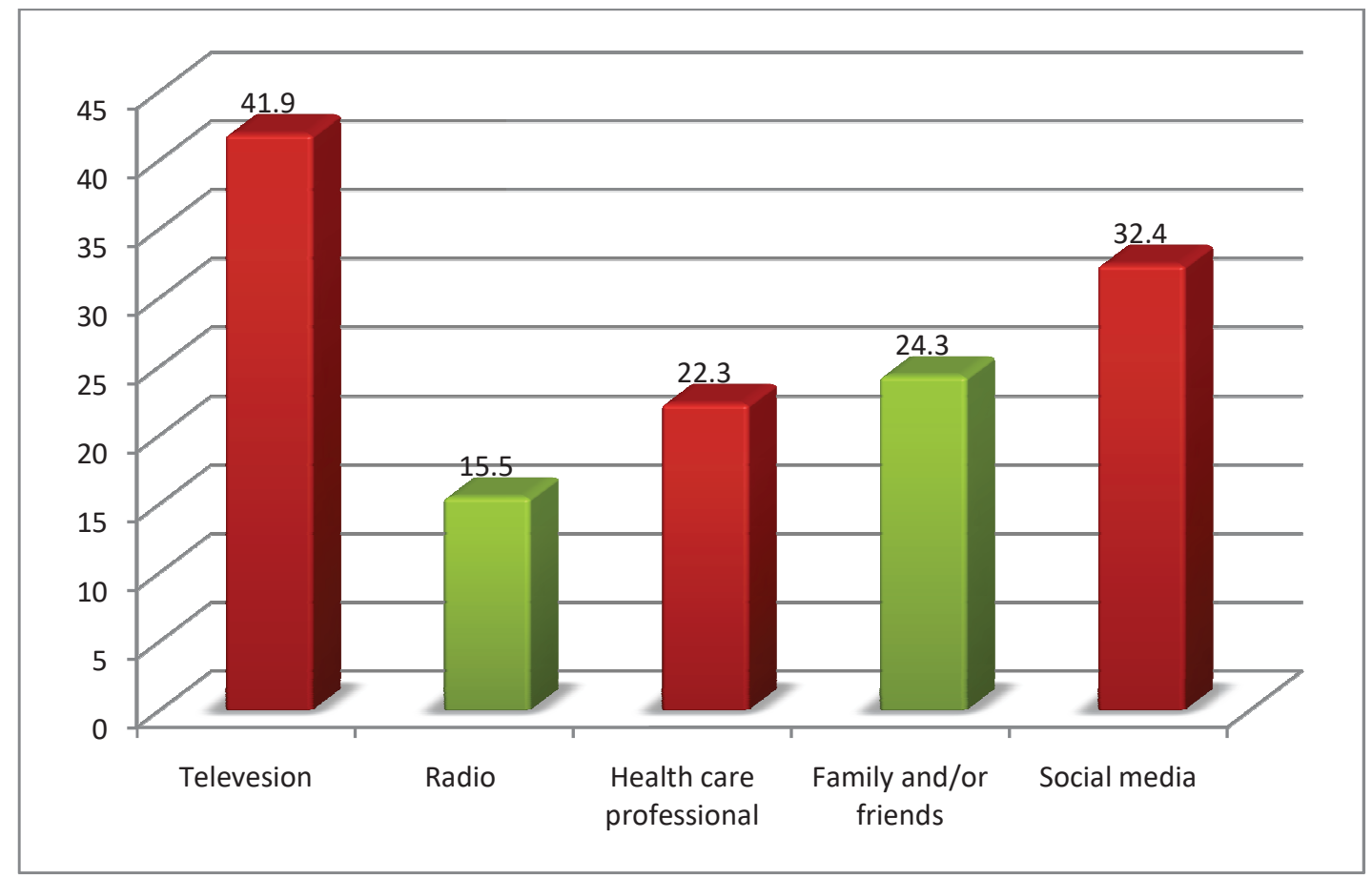

Figure 1. Sources of Nurses' information about covid-19

Table 3: Mean health belief model constructs scores for Covid-19 before and after the educational intervention $(\mathrm{n}=82)$

\begin{tabular}{|l|c|c|c|c|}
\hline \multirow{2}{*}{\begin{tabular}{l} 
Health Belief Model \\
\cline { 2 - 3 }
\end{tabular}} & $\begin{array}{c}|c| \\
\text { Before } \\
\text { Educational } \\
\text { intervention }\end{array}$ & $\begin{array}{c}\text { Paired } \\
\text { Educational } \\
\text { intervention }\end{array}$ & P- \\
t-test & value \\
\hline Perceived susceptibility & $20.73 \pm 5.59$ & $24.76 \pm 3.88$ & 55.938 & .000 \\
\hline Perceived benefits & $27.11 \pm 4.15$ & $40.59 \pm 14.50$ & 34.401 & .000 \\
\hline Perceived severity & $19.33 \pm 3.12$ & $22.22 \pm 4.03$ & 68.725 & .000 \\
\hline Perceived barriers & $26.38 \pm 6.37$ & $31.23 \pm 9.05$ & 45.156 & .000 \\
\hline Cues of action & $32.71 \pm 4.65$ & $36.84 \pm 5.22$ & 83.300 & .000 \\
\hline Self-efficacy & $21.68 \pm 2.76$ & $24.63 \pm 2.93$ & 92.658 & .000 \\
\hline Total & $198.95 \pm 20.13$ & $238.75 \pm 34.52$ & 80.689 & .000 \\
\hline
\end{tabular}

SD: Standard Deviation 
Table 4: Level of health belief model constructs about Covid-19 before and after the educational intervention $(\mathrm{n}=82)$

\begin{tabular}{|c|c|c|c|c|c|c|c|}
\hline \multirow{3}{*}{\multicolumn{2}{|c|}{ Level of Health Belief Model }} & \multicolumn{4}{|c|}{ Educational intervention } & \multirow{3}{*}{$\begin{array}{c}\text { Chi- } \\
\text { square } \\
\text { test }\end{array}$} & \multirow[t]{3}{*}{ P-value } \\
\hline & & \multicolumn{2}{|c|}{ Before } & \multicolumn{2}{|c|}{ After } & & \\
\hline & & No & $\%$ & No & $\%$ & & \\
\hline \multirow{3}{*}{$\begin{array}{l}\text { Perceived } \\
\text { susceptibility }\end{array}$} & Low & 79 & $96.3 \%$ & 7 & $8.5 \%$ & \multirow[t]{3}{*}{126.749} & \multirow[t]{3}{*}{$.000^{*}$} \\
\hline & Moderate & 1 & $1.2 \%$ & 30 & $36.6 \%$ & & \\
\hline & High & 2 & $2.4 \%$ & 45 & $54.9 \%$ & & \\
\hline \multirow{3}{*}{$\begin{array}{l}\text { Perceived } \\
\text { benefits }\end{array}$} & Low & 76 & $92.7 \%$ & 13 & $15.9 \%$ & \multirow[t]{3}{*}{104.596} & \multirow[t]{3}{*}{$.000^{*}$} \\
\hline & Moderate & 0 & $0.0 \%$ & 59 & $72.0 \%$ & & \\
\hline & High & 6 & $7.3 \%$ & 10 & $12.2 \%$ & & \\
\hline \multirow{3}{*}{$\begin{array}{l}\text { Perceived } \\
\text { severity }\end{array}$} & Low & 6 & $7.3 \%$ & 4 & $4.9 \%$ & \multirow[t]{3}{*}{40.254} & \multirow[t]{3}{*}{$.000^{*}$} \\
\hline & Moderate & 31 & $37.8 \%$ & 0 & $0.0 \%$ & & \\
\hline & High & 45 & $54.9 \%$ & 78 & $95.1 \%$ & & \\
\hline \multirow{3}{*}{$\begin{array}{l}\text { Perceived } \\
\text { barriers }\end{array}$} & Low & 14 & $17.1 \%$ & 12 & $14.6 \%$ & \multirow[t]{3}{*}{40.536} & \multirow[t]{3}{*}{$.000 *$} \\
\hline & Moderate & 42 & $51.2 \%$ & 7 & $8.5 \%$ & & \\
\hline & High & 26 & $31.7 \%$ & 63 & $76.8 \%$ & & \\
\hline \multirow[t]{3}{*}{ Cues of action } & Low & 13 & $15.9 \%$ & 7 & $8.5 \%$ & \multirow[t]{3}{*}{36.057} & \multirow[t]{3}{*}{$.000^{*}$} \\
\hline & Moderate & 46 & $56.1 \%$ & 14 & $17.1 \%$ & & \\
\hline & High & 23 & $28.0 \%$ & 61 & $74.4 \%$ & & \\
\hline \multirow[t]{3}{*}{ Self-efficacy } & Low & 16 & $19.5 \%$ & 17 & $20.7 \%$ & \multirow[t]{3}{*}{18.455} & \multirow[t]{3}{*}{$.000^{*}$} \\
\hline & Moderate & 58 & $70.7 \%$ & 35 & $42.7 \%$ & & \\
\hline & High & 8 & $9.8 \%$ & 30 & $36.6 \%$ & & \\
\hline
\end{tabular}

*. The Chi-square statistic is significant at the .05 level.

Table 5: Correlations between health belief model constructs and the educational intervention about Covid-19 $(\mathrm{n}=82)$.

\begin{tabular}{|l|c|c|}
\hline \multirow{2}{*}{ Health Belief Model } & \multicolumn{2}{|c|}{ Educational Intervention } \\
\cline { 2 - 3 } & r & P value \\
\hline Perceived susceptibility & .406 & 0.000 \\
\hline Perceived barriers & .889 & 0.000 \\
\hline Perceived benefits & .122 & 0.273 \\
\hline Perceived severity & .749 & 0.000 \\
\hline Cues of action & .808 & 0.000 \\
\hline Self-efficacy & .599 & 0.000 \\
\hline Preventive behavior & .887 & 0.000 \\
\hline Total & .808 & 0.000 \\
\hline
\end{tabular}


Table 6: Total health belief model scores about Covid-19 before and after educational intervention $(\mathrm{n}=82)$

\begin{tabular}{|c|c|c|c|c|c|c|}
\hline \multirow[b]{2}{*}{ Score of health belief model } & \multicolumn{4}{|c|}{ Educational intervention } & \multirow[t]{2}{*}{ Test } & \multirow[t]{2}{*}{$P$ value } \\
\hline & \multicolumn{2}{|c|}{ Before } & \multicolumn{2}{|c|}{ After } & & \\
\hline Mean \pm SD & \multicolumn{2}{|c|}{$198.88 \pm 20.13$} & \multicolumn{2}{|c|}{$238.75 \pm 34.52$} & $\mathrm{t}=89.44$ & $<0.000$ \\
\hline \multicolumn{5}{|l|}{ Level } & \multirow[t]{5}{*}{$X^{2}=37.83$} & \multirow[t]{5}{*}{$<0.000^{*}$} \\
\hline & No & $\%$ & No & $\%$ & & \\
\hline ○ Low & 13 & $15.9 \%$ & 11 & $13.4 \%$ & & \\
\hline ○ Moderate & 47 & $57.3 \%$ & 12 & $14.6 \%$ & & \\
\hline ○ High & 22 & $26.8 \%$ & 59 & $72.0 \%$ & & \\
\hline \multicolumn{5}{|l|}{ Correlation } & $r=0.81$ & $0.000^{* *}$ \\
\hline
\end{tabular}

Table 7: Nurses preventive behavior scores about Covid-19 before and after the educational intervention $(\mathrm{n}=82)$

\begin{tabular}{|c|c|c|c|c|}
\hline \multirow{2}{*}{$\begin{array}{l}\text { Preventive behavior about } \\
\text { Covid-19 }\end{array}$} & \multicolumn{2}{|c|}{ Educational intervention } & \multirow[t]{2}{*}{ Test } & \multirow{2}{*}{$\begin{array}{l}\text { P- } \\
\text { value }\end{array}$} \\
\hline & Before & After & & \\
\hline Mean \pm SD & $50.94 \pm 7.72$ & $58.50 \pm 10.38$ & $\begin{array}{l}\text { t-test }= \\
70.568\end{array}$ & .000 \\
\hline \multicolumn{5}{|l|}{ Level } \\
\hline $\begin{array}{ll}\text { ○ } & \text { Low } \\
\circ & \text { Moderate } \\
\circ & \text { High }\end{array}$ & $\begin{array}{l}15(18.3 \%) \\
51(62.2 \%) \\
16(19.5 \%)\end{array}$ & $\begin{array}{l}13(16.3 \%) \\
8(10.0 \%) \\
59(73.8 \%)\end{array}$ & $X^{2}=56.119$ & $.000 *$ \\
\hline $\begin{array}{l}\text { Correlation between nurses } \\
\text { Covid-19 and educational int }\end{array}$ & $\begin{array}{l}\text { preventive } \\
\text { ervention }\end{array}$ & lavior about & $r=0.89$ & $0.000 * *$ \\
\hline
\end{tabular}




\section{Discussion}

COVID-19 is widely reported

[18]to assess health care workers' $(14,012,449$ people worldwide), can be severe and fatal (mortality rate of 596,158 people worldwide is $4.25 \%$ ), and has an extremely high risk of human-to-human transmission (Riou\&Althaus, 2020) [15]. COVID-19 knowledge, as well as related health beliefs, self-efficacy, and preventive behaviors, are vital for diminishing infection rates, lowering mortality rates, and maintaining people's health and quality of life (Jia et al., 2020)[16].

The results of the current study showed that the ages of most of the nurses ranged between 22 and 28 years old with an average was $29.08 \pm 6.00$, and got a diploma in nursing, respectively. This result is in line with Eldesouky et al. [17] who conducted a quasi-experimental study in the Gastrointestinal Endoscopy Unit, Port Said Hospitals to evaluate the effect of an educational guidance intervention in relation to COVID-19 on nurses' knowledge and precautionary practices. They indicated that most of the nurses were less than 35 years old and had secondary nursing education. Similarly, a cross-sectional study was conducted in 2020, southwestern and northwestern Nigeria by Alao et al.

knowledge, attitudes toward, beliefs, and use of personal protective equipment to prevent SARS-CoV-2 infection in a resource-limited setting. They found that the mean age of the study group was 32.3 \pm 9.9 years.

In regards to nurses' COVID-19 knowledge scores, the current finding indicated that the knowledge of nurses had significantly improved in relation to COVID-19 as the evidence for the success of the educational intervention $(\mathrm{P}$ $<0.0001)$. Nurses' knowledge of COVID19 was also positively associated with the educational intervention, according to Pearson correlations $(\mathrm{P}<0.0001)$. The results have led to the acceptance of the specific hypothesis. This result is consistent with a quasi-experimental study performed at the Gastrointestinal Endoscopy Unit, Port Said Hospitals by Eldesouky et al. [17]to assess the influence of an educational guidance intervention regarding COVID-19 on nurses' knowledge and precautionary practices. They found improvement with a highly statistically significant difference between nurses' knowledge of COVID-19 before/after the educational intervention $(\mathrm{P}<0.001)$. The educational intervention was shown to be effective in improving 
nurses' knowledge, according to the findings. As a result, it is suggested that health education programs on COVID-19 be enhanced in addition to improving nurses' awareness and empower them to confront the disease.

Similarly, Abd-El Aziz Mohamed Madian \& Hamdi Sayed[19] conducted a randomized controlled educational study to assess the effect of an interactive digital educational intervention on COVID-19 knowledge and preventive behaviors among Damanhour University students. They discovered that after one and three months of the educational intervention about COVID-19, there was a statistically significant positive change in overall knowledge and preventative practices scores. Contrastly, in an Iranian study, the majority of respondents had sufficient knowledge about COVID19transmission routes and symptoms (Maleki et al., 2020)[20]. According to a Ugandan study, nearly most of respondents had sufficient knowledge (Olum et al., 2020)[21]. This variance could be explained by the characteristics of the sample, which included those with a diploma and were under the age of 28 .

The results of the current study showed that the best resources for nurses in regards to COVID-19 prevention are television and social media. Similarly,
Wahed et al., [22] found that health care practitioners who obtained information about the condition through social media had a higher level of knowledge. This may be due to the fact that educated individuals are more likely to use the internet. In addition, the Ugandan study found that HCWs who obtained information through news media such as television, radio, and newspapers had better knowledge (Olum et al., 2020)[21]. Al-Hanawi et al., (2020)[23] conducted a cross-sectional study in Saudi Arabia to assess the Saudi public's knowledge, attitudes, and practices toward COVID-19. They found that people gained awareness and knowledge about the disease and its transmission through television, news, and media platforms to protect themselves and their families.

According to a study conducted in the United Arab Emirates, there is a lack of knowledge regarding disease transmission, and the symptom was observed in a high proportion of $\mathrm{HCWs}$ (Bhagavathula et al., 2020)[24]. In contrast, Wahed et al. (2020)[22] stated that the knowledge level of HCWs on COVID-19 was good in a descriptive study conducted in Egypt to assess the knowledge, perception, and attitude of 
Egyptian Health Care Workers (HCWs) towards the COVID-19 disease.

The results of the current study showed that an educational intervention based on the health beliefs model of maternity nurses towards COVID-19 was critical, and plays a major role in internalizing preventive measures in emergency situations. This study concluded that the health belief model has an effective role in strengthening the precautionary measures of nurses to deal with and overcome the Corona virus.The results are similar to Elgzar et al. [25]who conducted an experimental study to investigate the effect of an educational intervention based on a health beliefs model on nursing students' knowledge and health beliefs in relation to COVID19, Najran University, Saudi Arabia. They showed that there was a statistically significant difference observed overall constructs of the health belief model with respect to COVID19 after the intervention. Further, the health belief model has been instrumental in improving nursing knowledge, perceived sensitivity, severity, and benefits in relation to COVID-19. Additionally, it increased their self-efficacy to overcome perceived barriers to practicing preventive measures while dealing with COVID-19.
The results of the current study showed that the preventive actions of nurses in relation to COVID-19 were significantly improved as a result of the educational intervention. This result is supported by Eldesouky et al. [17]to assess the impact of an educational guidance intervention on the precautionary practices of nurses in a gastro-intestinal endoscopy unit towards COVID-19. They reported that the nurses' precautionary practice after the educational intervention improved significantly with regard to COVID-19. Also, this result is consistent with a study conducted in Israel by Kaim et al. [26], who evaluate COVID-19 prevention techniques and found that educational interventions are an easy-to-implement design, an effective method, and have benefits for educating the community.This indicates that the educational intervention has been instrumental in strengthening the prevention and control measures for COVID-19. Hence, it is recommended that COVID-19 health education programs be implemented in the future to improve the practice and enable them to confront COVID-19 infection in the community sector.

Similarly, Abd-El Aziz Mohamed Madian \& Hamdi Sayed[19] conducted a randomized controlled educational 
study to assess the effect of an interactive digital educational intervention on COVID-19 knowledge and preventive behaviors among Damanhour University students. They discovered that after one and three months of the educational intervention about COVID-19, there was a statistically significant positive change in overall knowledge and preventative practices scores. This indicates that educational interventions are easy to design and implement, and effective and inexpensive strategies for the population.

\section{Conclusion}

The results of the study concluded that the results support the research hypothesis that the educational intervention based on the health beliefs model has a significant role in improving the knowledge and preventive practices of motherhood nurses towards COVID19s, with significant differences before and after the educational intervention. There was a significant positive correlation between the nurses' knowledge and their precautionary practices scores with the educational intervention based on the health beliefs model.

\section{Recommendations}

1. The results suggest that targeted health education interventions should be directed at health care workers who are particularly at risk of contracting COVID-19.

2. Periodic educational program for nursing staff in Obstetrics and Gynecology Department regarding COVID-19 and importance of vaccination.

3. Prepared booklets about safety precautions regarding COVID-19 should be available to all nurses who work in Obstetrics and Gynecology Department.

Further researches:

1. Preparing guidelines for pregnant women regarding safety precautions against COVID-19.

2. Replication of the study on large representative probability sample is highly recommended in different maternity hospitals to achieve more generalization of the results.

\section{Implications for Nursing \& Health}

\section{Policy}

Workers in the health sector should be targeted for health-education interventions since they are at a higher risk of getting COVID-19

\section{References}

1. Taiwan centers for disease control. COVID-19. Available at: https://www.cdc.gov.tw/ [assessed July 18, 2020]. 
2. Dey, S. K., Rahman, M. M., Siddiqi, U. R., \&Howlader, A. Analyzing the epidemiological outbreak of COVID-19: A visual exploratory data analysis approach. Journal of medical virology, 2020; 92(6), 632-638.

3. Kang, L., Ma, S., Chen, M., Yang, J., Wang, Y., Li, R., \& Liu, Z. (2020). Impact on mental health and perceptions of psychological care among medical and nursing staff in Wuhan during the 2019 novel coronavirus disease outbreak: A cross-sectional study. Brain, behavior, and immunity, 2020; 87: 11-17.

4. Wang, Y., Wang, Y., Chen, Y., \& Qin, Q. (2020). Unique epidemiological and clinical features of the emerging 2019 novel coronavirus pneumonia (COVID-19) implicate special control measures. Journal of medical virology, 2020; 92(6), 568-576.

5. Sun, P., Lu, X., Xu, C., Sun, W., \& Pan, B. Understanding of COVID-19 based on current evidence. Journal of medical virology, 2020; 92(6), 548551.

6. Tu, Z. H., He, J. W., \& Zhou, N. Sleep quality and mood symptoms in conscripted frontline nurse in Wuhan, China during COVID-19 outbreak: A cross-sectional

study. Medicine, 2020; 99(26).

7. Tourer, R. W., Jones, I., Rosenbloom, S. T., Slovis, C., \& Ward, M. J. Electronic personal protective equipment: a strategy to protect emergency department providers in the age of COVID-19. Journal of the American Medical Informatics Association, 2020; 27(6), 967-971.

8. Mukhtar, S. Mental health and emotional impact of COVID-19: Applying Health Belief Model for medical staff to the general public of Pakistan, 2020.

9. World Health Organization. Coronavirus disease ( COVID-19) outbreak: rights, roles and responsibilities of health workers, including key considerations for occupational safety and health: interim guidance, 2020 (No. WHO/2019-

nCov/HCW_advice/2020.2). World Health Organization.

10. Gan, W. H., Lim, J. W., \&Koh, D. Preventing intra-hospital infection and transmission of coronavirus disease 2019 in health-care workers. Safety and health at work, 2020; 11(2), 241-243.

11. World Health Organization. Infection prevention and control during health 
care when novel coronavirus $(\mathrm{nCoV})$ infection is suspected: interim guidance, 2020 (No. WHO/2019nCoV/IPC/2020.2). World Health Organization.

12. Wu, Z., \&McGoogan, J. M. Characteristics of and important lessons from the coronavirus disease 2019 (COVID-19) outbreak in China: summary of a report of 72314 cases from the Chinese Center for Disease Control and Prevention. Jama, 2020; 323(13): 1239-1242.

13. McEachan, R., Taylor, N., Harrison, R., Lawton, R., Gardner, P., \& Conner, M. Meta-analysis of the reasoned action approach to understanding health behaviors. Annals of Behavioral Medicine, 2016; 50(4), 592-612.

14. Khoramabadi, Dolatian, Hajian, Zamanian, Taheripanah, Sheikhan, Mahmoodi, and Seyedi-Moghadam. Effects of education based on health belief model on dietary behaviors of Iranian pregnant women glob $\mathrm{j}$ health sci. 2016 feb; 8(2): 230-239.

15. Riou, J., \&Althaus, C. L. The pattern of early human-to-human transmission of Wuhan 2019 novel coronavirus (2019-nCoV), December 2019 to January 2020.
Eurosurveillance, 2020; 25(4), 2000058.

16. Jia, Q., Shi, S., Yuan, G., Shi, J., Shi, S., \& Hu, Y. Analysis of knowledge bases and research hotspots of coronavirus from the perspective of mapping knowledge domain. Medicine, 2020; $\quad$ 99(22), e20378.

17. Eldesouky E. I, Hafez E. M., Aml Ahmed Mohammed, A. A. Effect of educational Guidelines Intervention regarding COVID -19 on nurses knowledge and precautionary practices in gastrointestinal endoscopes. Egyptian Journal of Health Care, 2021; 12(4):318-331.

18. Alao, M. A., Durodola, A. O., Ibrahim, O. R., \&Asinobi, O. A. Assessment of Health Workers' Knowledge, Beliefs, Attitudes, and Use of Personal Protective Equipment for Prevention of COVID-19 Infection in Low-Resource Settings. Advances in Public Health, 2020.

19. Abd-El AzizMohamedMadian, A., \&HamdiSayed, S. Effect of Interactive Digital-Based Educational Intervention on knowledge, Misconceptions, and Preventive Practices of COVID-19 among Damanhour University 
Students. Egyptian Journal of Health

Care, 2021; 12(1), 1136-1154.

20. Maleki, S., Najafi, F., Farhadi, K., Fakhri, M., Hosseini, F., \&Naderi, M. (2020). Knowledge, attitude, and behavior of health care workers in the prevention of COVID-19, 2020.

21. Olum, R., Chekwech, G., Wekha, G., Nassozi, D. R., \&Bongomin, F. Coronavirus disease-2019: knowledge, attitude, and practices of health care workers at Makerere University Teaching Hospitals, Uganda. Frontiers in public health, 2020; 8:181.

22. Al-Hanawi, M. K., Angawi, K., Alshareef, N., Qattan, A., Helmy, H. Z., Abudawood, Y., \&Alsharqi, O. Knowledge, attitude and practice toward COVID-19 among the public in the Kingdom of Saudi Arabia: a cross-sectional study. Frontiers in public health,2020; 8, 217.

23. Wahed, W. Y. A., Hefzy, E. M., Ahmed, M. I., \&Hamed, N. S. Assessment of knowledge, attitudes, and perception of health care workers regarding COVID-19, a crosssectional study from Egypt. Journal of community health, 2020; 45(6), 1242 1251.

24. Bhagavathula, A. S., Aldhaleei, W. A., Rahmani, J., Mahabadi, M. A., \&Bandari, D. K. Knowledge and perceptions of COVID-19 among health care workers: a cross-sectional study. JMIR public health and surveillance, 2020; 6(2), e19160.

25. Elgzar, W. T., Al-Qahtani, A. M., Elfeki, N. K., \& Ibrahim, H. A. COVID-19 Outbreak: Effect of an Educational Intervention Based on Health Belief Model on Nursing Students' Awareness and Health Beliefs at Najran University, Kingdom of Saudi Arabia. African journal of reproductive health, 2020; 24(2), 78-86.

26. Kaim, A., Jaffe, E., Siman-Tov, M., Khairish, E., \&Adini, B. Impact of a Brief Educational Intervention on Knowledge, Perceived Knowledge, Perceived Safety, and Resilience of the Public During COVID-19 Crisis. International journal of environmental research and public health, 2020; 17(16), 5971. 